\title{
Changes of protein glycosylation in the course of
}

\section{radiotherapy}

Eszter Tóth ${ }^{\mathrm{a}, \mathrm{b}}$, Károly Vékey ${ }^{\mathrm{c}}$, Olivér Ozohanics ${ }^{\mathrm{a}}$, Anita Jekő ${ }^{\mathrm{a}}$, Iwona Dominczyk ${ }^{\mathrm{d}}$, Piotr Widlak $^{\mathrm{d}}$, László Drahos ${ }^{\mathrm{a} *}$

${ }^{a}$ MS Proteomics Research Group, Institute of Organic Chemistry, Research Centre for Natural Sciences, Hungarian Academy of Sciences, Budapest, Hungary

${ }^{b}$ Semmelweis University, School of Ph.D. Studies, Budapest, Hungary

${ }^{c}$ Core Technologies Centre, Research Centre for Natural Sciences, Hungarian Academy of Sciences, Budapest, Hungary

${ }^{d}$ Maria Sklodowska-Curie Memorial Cancer Center and Institute of Oncology, Gliwice Branch, Gliwice, Poland

\begin{abstract}
This is the first study of changes in protein glycosylation due to exposure of human subjects to ionizing radiation. Site specific glycosylation patterns of 7 major plasma proteins were analyzed; 171 glycoforms were identified; and the abundance of 99 of these was followed in the course of cancer radiotherapy in 10 individual patients. It was found that glycosylation of plasma proteins does change in response to partial body irradiation ( $\sim 60 \mathrm{~Gy})$, and the effects last during follow-up; the abundance of some glycoforms changed more than twofold. Both the degree of changes and their time-evolution showed large inter-individual variability.
\end{abstract}

*To whom correspondence should be addressed:

László Drahos

Research Centre for Natural Sciences, Hungarian Academy of Sciences 
H-1519 Budapest, P.O. Box 286. Hungary

E-mail: drahos.laszlo@ttk.mta.hu

Phone: $+36-1-382-6542$

\section{HIGHLIGHTS:}

- first human study to show that ionizing radiation does change protein glycosylation

- glycosylation of 7 major plasma proteins in 10 individual cases were followed

- changes of protein glycosylation in response to radiotherapy last for several weeks

KEYWORDS: head and neck cancer, glycosylation, proteomics, glycosylation pattern, radiotherapy 


\section{Introduction}

Radiation has been always a very important factor influencing living organisms. Radiation comes from accidental, intentional or natural sources; we can differentiate environmental, industrial, occupational (in wars) radiation, radiological terror and medicinal radiotherapy.

In radiobiology there is an increasing interest in proteomics nowadays [1-3]. The response for radiation was often studied on the genome level. However DNA damage is only part of the picture; changes in cellular structure; in protein composition of cells and biological fluids are also needed to understand molecular mechanisms and micro-environmental consequences of radiation. Furthermore, radiation may induce changes in higher order organisms. Beside genetics, proteomics may offer new insights, describing new pathophysiological pathways or discovering new biomarker candidates [4-10] to assess the influence of radiation on living, multicellular organisms. Note, that especially in multicellular organisms, the long-term response of the organism to radiation may even be more important, than radiation damage itself. Cell-cell communication; partly mediated by biological fluids like blood, often involves glycosylation. Bearing these in mind, in the present paper we focus on evaluating long-term glycosylation changes in plasma proteins.

Diversity of proteins and types of molecular pathways they are involved in are enormously expanded due to post-translational modifications. Effects of radiation has already been studied in case of phosphorylation [6, 11-13], acetylation [12], ubiquitination [14], carbonylation [15, 16], nitrosylation $[15,16]$ and glycosylation [17-20] in different tissues and biofluids and in some cases significant alterations were found.

Glycosylation is one of the most important and most common post-translational modification of proteins. Glycosylation has important biological roles: it takes part in transport of proteins, immune response, communication between cells and several human plasma glycoproteins have been proved to be biomarkers for different diseases [21-24]. From analytical point of 
view there are two ways (and combination of these) to characterize glycosylation: 1) Averaging glycosylation data: before analysis glycans are removed from proteins using specific enzymes (e.g.: $N$-glycans are cleaved with PNGaseF) or acidic hydrolysis, and then released glycan mixture is characterized by the number of antennas and sialic acid residues. In this case important information about attachment sites of glycans is lost. 2) Site-specific glycosylation patterns are carrying more and different biological information: proteins are digested using endoproteases (e.g.: trypsin) and resulted glycopeptides are analyzed, therefore glycosylation sites and site-specific distribution of glycans can also be determined. [25-28]

To our knowledge there are only a few studies published about the relationship between glycosylation and ionizing radiation. 1) Dorsal skin irradiation of mice was performed at different doses (20, 40 and $80 \mathrm{~Gy})$ and serum proteins were analyzed using two dimensional differential in-gel electrophoresis. Glycans were analyzed after they were removed from the proteins using mass spectrometry. Shifts in the isoelectric point $(p I)$ were observed $[17,29]$ possibly caused by changes in glycosylation, and decrease in biantennary structure, increase in multiantennary $N$-glycans, outer branch fucosylation and sialylation was found [17]. However, because averaging glycosylation was studied, there was no information whether changes in glycosylation involved all, or only some specific proteins. 2) In another study [20] mice were exposed to ionizing radiation $(0,3,6$ and $10 \mathrm{~Gy})$ and plasma glycoproteins were analyzed using lectins. Time and dose dependent alterations of glycoproteins containing galactose, $\mathrm{N}$-acetylgalactosamine and mannose were found, however there was no significant difference in the plasma glycoprotein level. 3) In colon cancer cells, correlation between radiation-mediated sialylation of integrin $\beta 1$ (glycosylated cell surface protein) and increased radio-resistance was observed $[18,19]$.

In the current study site-specific glycosylation pattern of plasma proteins was analyzed from human samples. Patients suffering from head and neck cancer were treated with radiotherapy 
(RT). Site-specific glycosylation pattern was determined from samples collected before, during and after the treatment. We observed that glycosylation of various proteins changed significantly, which may help to better understand the molecular response of the human body for radiation.

\section{Materials and methods}

\subsection{Samples and chemicals}

Ten patients (Caucasians; 50-80-year-old, median 61 years; 7 men) with head and neck squamous cell carcinoma (HNSCC) located in larynx (7) or pharynx (3) were enrolled into the study. All patients were subjected to intensity-modulated RT (IMRT) using 6-MV photons. Total radiation dose delivered to the gross tumor volume $\left(20-148 \mathrm{~cm}^{3}\right)$ was in the range of 51 72 Gy (median 67.2 Gy); overall treatment time was 22-50 days (median 39 days) with dose fractions 1.8-3 Gy. Three consecutive blood samples (5 mL each) were collected from each patient: pre-treatment sample A, post-treatment sample B collected in the last day of the treatment (i.e. after receiving total dose) and post-treatment sample C collected 1-1.5 month after the end of RT. Plasma specimen was isolated from EDTA-treated blood after centrifugation at $2,000 \mathrm{~g}$ for 15 minutes, and then stored at $-80{ }^{\circ} \mathrm{C}$ before analysis. The study was approved by the appropriate Ethics Committee and all participants provided informed consent indicating their conscious and voluntary participation.

1,4-dithio-L,D-threitol (DTT) and 2-iodoacetamide (IAA) were obtained from Fluka Chemie GmbH (Sigma-Aldrich ${ }^{\circledR}$, Zwijndrecht, Netherlands). RapiGest SF (lyophilized sodium-3-[(2methyl-2-undecyl-1,3-dioxolan-4-yl)-methoxyl]-1-propane-sulfonate) was purchased from Waters (Milford, MA, USA). Mass spectrometry grade trypsin was purchased from Promega Corporation (Madison, WI, USA).

All other reagents were purchased from Sigma-Aldrich ${ }^{\circledR}$ (St. Louis, MO, USA). 


\subsection{Immunoaffinity depletion of plasma samples}

To reduce sample complexity, two high abundance proteins: albumin and IgG were removed from human plasma with Agilent Multiple Affinity Removal Spin Cartridge HSA/IgG (Agilent Technologies, Santa Clara, CA, USA).

$30 \mu \mathrm{L}$ plasma sample was loaded onto the cartridge and manufacturer's standard protocol was followed. At the end $\mathrm{K}_{2} \mathrm{HPO}_{4}$ and citric acid were added to the diluted samples to prevent aggregation (30-30 $\mathrm{mM}$ concentration in the samples), and samples were concentrated with 10 $\mathrm{kDa}$ centrifuge filters. After filtration, volume of the depleted plasma sample was $25 \mu \mathrm{L}$.

\subsection{Fractionation of depleted plasma samples}

Fractionation of depleted plasma samples was performed using Acquity UPLC ${ }^{\circledR}$ System (Waters, Milford, MA, USA).

Poros R2 HPLC column (Poly(Styrene-Divinylbenzene, $10 \mu \mathrm{m}, 2.1 \times 100 \mathrm{~mm}$, Applied Biosystems, Foster City, CA, USA) was used, and depleted plasma samples were injected in $15 \mu \mathrm{L}$ volume. The column temperature was $65^{\circ} \mathrm{C}$, the flow rate was $1 \mathrm{~mL} / \mathrm{min}$. The gradient was the following: starting with $20 \%$ B for $0.7 \mathrm{~min}$, then a $15 \mathrm{~min}$ long gradient from $20 \%$ to $70 \%$ solvent $\mathrm{B}$, increasing to $95 \%$ solvent $\mathrm{B}$ in $0.1 \mathrm{~min}$, washing for $1.5 \mathrm{~min}$, returning to $20 \% \mathrm{~B}$ in $0.1 \mathrm{~min}$ and equilibration for $6 \mathrm{~min}$. Solvent $\mathrm{A}$ was water containing $0.07 \mathrm{v} / \mathrm{v} \%$ trifluoroacetic acid and solvent B was acetonitrile containing $0.07 \% \mathrm{v} / \mathrm{v}$ trifluoroacetic acid. $500 \mu \mathrm{L}$ fractions were collected manually from 4.5 to $5.5 \mathrm{~min}$ (two half minute fractions). To neutralize TFA and to prevent aggregation $1.3 \mu \mathrm{L} \mathrm{NH}$ solution $(25 \mathrm{w} / \mathrm{w} \%)$ and $1.8 \mu \mathrm{L}$ $\mathrm{K}_{2} \mathrm{HPO}_{4}$ solution $(500 \mathrm{mM})$ were added to the fractions, and fractions were concentrated to 30 $\mu \mathrm{L}$ with SpeedVac (miVac Duo Concentrator, Genevac Ltd., Ipswich, Suffolk, UK). 
Details of this fractionation method and it's benefits during the analysis of glycoproteins was described before [30].

\subsection{In-solution digestion}

Concentrated fractions were digested as the following: after adding $5 \mu \mathrm{L} \mathrm{NH}_{4} \mathrm{HCO}_{3}$ solution (200 $\mathrm{mM})$ proteins were unfolded and reduced using $3 \mu \mathrm{L}$ RapiGest SF solution $(0.5 \mathrm{w} / \mathrm{v} \%)$ and $2 \mu \mathrm{L}$ DTT solution $(100 \mathrm{mM})$ for $30 \mathrm{~min}$ at $60{ }^{\circ} \mathrm{C}$. Proteins were alkylated using $4 \mu \mathrm{L}$ $\mathrm{NH}_{4} \mathrm{HCO}_{3}$ solution $(200 \mathrm{mM})$ and $2 \mu \mathrm{L}$ IAA solution $(200 \mathrm{mM})$ for $30 \mathrm{~min}$ at room temperature in dark. Digestion was performed by adding $1.5 \mu \mathrm{L}$ trypsin solution $(40 \mu \mathrm{M})$ for 180 min at $37{ }^{\circ} \mathrm{C}$. Digestion was stopped by adding $1.5 \mu \mathrm{L}$ formic acid, followed by $30 \mathrm{~min}$ incubation at $37{ }^{\circ} \mathrm{C}$. Samples were centrifuged at $13500 \mathrm{rpm}$ (corresponding to $17000 \mathrm{~g}$ ) for $10 \mathrm{~min}$.

\section{5 nanoLC-MS(/MS) analysis}

Digested fractions were analyzed using nanoAcquity UPLC (Waters, Milford, MA, USA) coupled to a high resolution QTOF Premier mass spectrometer (Waters, Milford, MA, USA). The chromatographic conditions were the following: Symmetry C18 trap column $(180 \mu \mathrm{m}$ i.d. $\times 20 \mathrm{~mm}$, Waters Milford, MA, USA) and reversed-phase analytical column $(\mathrm{C} 18,1.7 \mu \mathrm{m}$ BEH particles, $75 \mu \mathrm{m}$ i.d. $\times 200 \mathrm{~mm}$, Waters, Milford, MA, USA) were used. Column temperature was $55{ }^{\circ} \mathrm{C}$. Using $250 \mathrm{~nL} / \mathrm{min}$ flow rate the gradient started from $3 \%$ to $8 \% \mathrm{~B}$ in 4 min, followed by a 65 min long gradient going to $40 \%$ solvent B. Washing was performed using $450 \mathrm{~nL} / \mathrm{min}$ flow rate and a 2 min long gradient from 40 to $75 \%$ solvent $\mathrm{B}$, keeping here for $18 \mathrm{~min}$. Finally, after returning to $3 \% \mathrm{~B}$ in $2 \mathrm{~min}$, equilibration was done for $18 \mathrm{~min}$. Solvent A was water containing $0.1 \mathrm{v} / \mathrm{v} \%$ formic acid and solvent B was acetonitrile containing $0.1 \mathrm{v} / \mathrm{v} \%$ formic acid. 
Protein composition of the digested fractions was determined with tandem mass spectrometry using data dependent analysis of the resulted peptides. Conditions were the following: Electrospray ionization mode was used, capillary voltage was $2.3 \mathrm{kV}$, nanoflow 1 bar, source temperature $90{ }^{\circ} \mathrm{C}$, cone voltage $35 \mathrm{~V}$. Collision gas was argon, at $4.05 \times 10^{-3}$ mbar. Collision energy was varied in the $7-70 \mathrm{eV}$ range. The parent ion was selected in the $400-1800 \mathrm{~m} / \mathrm{z}$ range, MS/MS spectra were acquired in the $50-2000 \mathrm{~m} / \mathrm{z}$ range.

Glycosylation sites and major site-specific glycoforms were identified also with tandem mass spectrometry. Most of the parameters were the same as described above, however the parent ion was selected in the $780-2000 \mathrm{~m} / \mathrm{z}$ range and MS/MS spectra were acquired in the 150 $3000 \mathrm{~m} / \mathrm{z}$ range. Collision energy was varied in the 5-55 eV range. Minor glycoforms and relative quantitation were measured with single stage mass spectrometry in extended dynamic range mode. Scans were acquired in the $500-2000 \mathrm{~m} / \mathrm{z}$ range.

Site-specific glycosylation pattern of the proteins was analyzed by the method described earlier [31].

\subsection{Data evaluation}

Protein content of the fractions was identified from MS/MS measurements using ProteinLynx Global Server v.2.3 (Waters, Milford, MA, USA) and searched against v.2011_10 of SwissProt sequence database with human taxonomy using Mascot Server v.2.2 (Matrix Science, London, UK). One missed cleavage was allowed, carbamidomethyl cysteine was set as fixed modification.

MS/MS spectra corresponding to major glycopeptides were automatically evaluated by our computer software GlycoMiner v.1.13 Beta [32]. Minor glycopeptide identification and relative glycopeptide quantitation were performed from MS measurements using the in-house developed computer software GlycoPattern v.2.0 [31]. 


\section{Results and discussion}

The effect of exposure to ionizing radiation on plasma proteins glycosylation was studied for first time in case of human samples. Site-specific glycosylation patterns of 7 abundant plasma proteins were determined in the case of 10 patients. For each patient samples were collected before and after exposure. Pre-treatment sample A was considered as a reference for each individual person; sample B represents the change induced in glycosylation due to irradiation; while sample $\mathrm{C}$ allowed addressing potential long-term effects of the treatment (1-1.5 months). Seven abundant plasma proteins were selected for analysis: Alpha-1-acid glycoprotein (A1AG1_HUMAN, A1AG2_HUMAN, two genetic variants), alpha-2-HSglycoprotein (fetuin, FETUA_HUMAN), beta-2-glycoprotein 1 (apolipoprotein $\mathrm{H}$, APOH_HUMAN), complement factor H (CFAH_HUMAN), haptoglobin (HPT_HUMAN), kininogen-1 (KNG1_HUMAN), and serotransferrin (TRFE_HUMAN). Some of these glycoproteins contain various glycosylation sites, which were always treated individually. Presence and intensity of complex glycan structures (different glycoforms) on $\mathrm{N}$ glycopeptides were determined and confirmed by MS/MS measurements of the respective glycopeptides. Relative abundance of the various components was based on the chromatographic peak area of the respective MS signals. Subsequently these were normalized to the sum of the abundance of all glycoforms identified in the given chromatographic run.

In the course of MS/MS studies we have identified altogether 171 glycoforms characterizing the 7 selected proteins. Among these we have selected the 99 glycoforms for a quantitative study (those above the limit of quantification). The list of these components, and their relative abundances in the "reference" pre-treatment sample A, averaged over the 10 patient samples, are shown in Table A. Glycoform abundances vary between the various individuals - the average relative standard deviation (biological variability considering the 10 most intense 
peaks) is $29 \%$. Reproducibility of individual glycoform abundances (variability of sample preparation and instrumental analysis) is on average $17 \%$, from which reproducibility of instrumental analysis is $8 \%$, using 3-3 replicates. In order to illustrate results and to study the influence of radiotherapy on protein glycosylation, first results for one individual will be discussed. Subsequently we shall look at glycosylation in other individuals to see, how these could be generalized.

Fig. A shows the glycosylation pattern (relative abundance of various glycoforms) of two proteins (alpha-2-HS-glycoprotein and serotransferrin) in the case of a given individual. Dark blue indicates abundances before irradiation (sample A); blue that in the course of radiotherapy (sample B); while light blue columns that one month after radiotherapy (sample C). The three glycosylation patterns are different, showing that radiotherapy does influence glycosylation patterns of various proteins. For example Fig. A shows that the relative abundance of the biantennary disialylated (BiS2) glycoform at glycosylation site $1\left({ }^{432} \mathrm{~N}\right)$ of serotransferrin was $16 \%$ before radiotherapy in the studied individual. This relative abundance decreased to $11 \%$ (by $31 \%$ ) during radiotherapy. One month after finishing radiotherapy abundance of this glycoform increased (to 13\%), but did not yet reach its original abundance. Fig. A illustrates that glycosylation in case " $\mathrm{C}$ " is between that of " $\mathrm{A}$ " and "B", the same was observed in various other cases as well. This suggests, that after irradiation is finished, the glycosylation pattern starts to return to "normal" (i.e. to that before irradiation); but one month time is not sufficient for this. Other glycoproteins and other persons show analogous changes, although the results quantitatively may be different.

Changes in the glycosylation pattern due to radiotherapy are shown in a more quantitative manner in Fig. B. Here we depict changes in the abundance of various glycoforms (i.e. those listed in Table A) in the course of radiotherapy. In the horizontal axis the change in glycoform abundance during radiotherapy is shown (that compared to its value before radiotherapy 
started, i.e. abundance measured in sample B compared to that in sample A). This shows the magnitude of change in the various glycoform abundances due to radiotherapy; measured when a large amount of radiation dose was already absorbed by the individual. The vertical axis shows the glycoform abundance one month after radiotherapy finished compared to the abundance before radiotherapy (abundance measured in sample C compared to that in sample A). The figure shows that some glycoforms increased 5-fold, some others decreased 5-fold; most showed smaller changes. In the present pilot study, the limited number of patient samples preclude a general conclusion, which proteins and which glycoforms are most influenced by radiotherapy. This should be established in a subsequent, full scale clinical study.

Fig. $\mathrm{B}$ shows that there is a good linear relationship $\left(\mathrm{R}^{2}=0.8292\right)$ between $\mathrm{B} / \mathrm{A}$ and $\mathrm{C} / \mathrm{A}$ values. Linear correlation between $\mathrm{C} / \mathrm{A}$ and $\mathrm{B} / \mathrm{A}$ means, that the change in glycoform intensity (compared to the respective value before radiotherapy) during and ca. 1 month after radiotherapy are correlated. If the slope is unity, this indicates that radiotherapy induces a certain change; and this change becomes fixed (will not change even one month after treatment). If the slope is zero, this indicates that the change in glycosylation goes back to the "original" value (that before radiotherapy) as soon as radiotherapy is finished. The slope is close to, but less than unity (0.87). This suggest that changes in glycosylation induced by radiotherapy last for a long time. After radiotherapy is finished, protein glycosylation starts to return to the "normal" value (i.e. to that measured before irradiation). The value of the slope suggests, that ca. $87 \%$ of radiation-induced changes in glycosylation are still present one month after irradiation was finished. This implies that the effect of radiotherapy on plasma protein glycosylation is likely to last for several months.

The results described above are qualitatively similar to all other persons studied. Some glycoforms increase, some others decrease due to radiotherapy. After irradiation, 
glycosylation slowly starts to return to "normal". One month after irradiation is finished, the results are somewhere in between that before and during irradiation. One typical example for change in glycosylation can be detected in the case of complement factor $\mathrm{H}(\mathrm{CFAH})$, a protein responsible for activation of the alternate pathway of the complement system. Glycosylation of CFAH shows increased fucosylation on all of its glycosylation sites, but the rates of change are very different for the different sites. The fucosylation change for CFAH glycosylation sites was also observed in liver diseases [33].

Glycosylation changes are illustrated in Fig. C, which shows glycoform abundances for all 10 individuals studied. To account for differences between individuals, glycoform abundances during and after radiotherapy were compared to the value measured before radiotherapy for each individual. Blue squares (mostly overlapping and thus forming a wide line) indicate the abundance of all studied glycoforms during radiotherapy, compared to that before the start of radiotherapy (B/A). These data (altogether nearly 800 abundance ratios) are sorted according to their value. The orange open circles in the figure show the corresponding C/A ratios (i.e. one month after radiotherapy, compared to that before). When the value of the blue squares is over unity (i.e. a certain glycoform shows increased abundance due to radiotherapy), there is a high $(\sim 77 \%)$ probability, that the corresponding yellow circle will also be over unity (i.e. the glycoform will have increased abundance even one month after radiotherapy was finished). In an analogous manner, when the value of the blue squares is less than unity (i.e. radiotherapy depletes abundance of a certain glycoform) the orange circle will also be below unity (i.e. will remain depleted for a long time). Note, mainly due to random errors, smaller than $\sim 20 \%$ changes in glycoform abundance could not be evaluated.

During the glycosylation analysis of irradiated mice serum samples Chaze et al. [17] observed the decrease of biantennary structures; and increase of tri- tetra- and pentaantennary $\mathrm{N}$ glycans, outer branch fucosylation and sialylation. No difference was measured in the 
expression of genes involved in the synthesis of biantennary $\mathrm{N}$-glycans, however genes implicated in the multiantennary $N$-glycan synthesis were found to be overexpressed. However, Chaze et al. analyzed only removed glycans, therefore information about the proteins containing these glycan structures was lost. Only site-specific glycosylation analysis could give the answer, whether the changes in the intensity of different glycan structures were caused by changes in the abundance of modified proteins with these particular structures or by increases in particular structures linked to different proteins. Note that both in human and in mouse studies a small, few $\mathrm{cm}^{2}$ surface was irradiated. However, in mouse this represents ca. $10 \%$ of body volume (so irradiation can be considered systemic); while in humans it is only ca. $0.01 \%$ body volume; so it is clearly localized.

Analyzing site-specific data of all human individuals we observed that intensity of $44 \%$ of glycoforms increased and $56 \%$ decreased. Correlation between the direction of intensity changes (increasing or decreasing) and the following parameters was studied: a) different proteins, $b$ ) different complex sugar types on glycoforms (number of antennas, number of sialic acids and fucoses) and c) different human individuals, but in contrast to the mice samples no correlation was found. This means that the study of site-specific glycosylation pattern is essential in case of human samples for each glycoform of any protein and individual, because from the cleaved mixture of sugars we couldn't recognize the effect of irradiation on glycosylation.

\section{Conclusions}

This is the first human study to show that local body irradiation during cancer radiotherapy does change glycosylation of plasma proteins. As glycosylation is involved in various immunological processes and cell-cell communications, this may have impact on efficacy and side effects of radiotherapy. We have studied glycosylation of 7 major plasma proteins in 10 
individual cases. In the course of the study we have followed changes in the abundance of 99 glycoforms during radiotherapy. All studied proteins showed glycosylation changes- in most cases $20-30 \%$ change in glycoform abundances were observed due to irradiation, although in many cases larger than twofold changes were also found. Note, that these are plasma proteins - i.e. reflect changes in the organism, and not directly related to tissue damage (which occurs in a small body volume only). Compared to other post-translational modification studies these changes can be considered highly significant: in cells after treatment with 10 Gy ionizing radiation only about $1 \%$ of quantified phosphoproteins was found to be upregulated more than 2-fold, and about 3.5\% were upregulated over 1.5-fold [12]. The results show that radiotherapy changes protein glycosylation for a long period: One month after finishing radiotherapy, the glycosylation profile only starts to return to "normal" (i.e. that before radiotherapy commenced), which indicated long-term effects of radiation. The results suggest that therapeutic radiation induces changes in the whole human body, and these changes last for a long period (several weeks or months). The present experiments showed large interindividual differences. The number of individuals in the present study was insufficient to determine, if glycosylation changes may be used to assess the efficiency of radiotherapy; or the healing capacity of the individual.

\section{Acknowledgement}

This work has been supported by the Hungarian Scientific Research fund (grant No. OTKA83857). We thank the Core Technologies Centre of the Research Centre for Natural Sciences for the use of instrumentation. 


\section{References}

[1] O. Azimzadeh, M.J. Atkinson, S. Tapio, Proteomics in radiation research: present status and future perspectives, Radiat. Environ. Biophys. 53 (2014) 31-38.

[2] S. Tapio, S. Hornhardt, M. Gomolka, D. Leszczynski, A. Posch, S. Thalhammer, M.J. Atkinson, Use of proteomics in radiobiological research: current state of the art, Radiat. Environ. Biophys. 49 (2010) 1-4.

[3] D. Leszczynski, Radiation proteomics: A brief overview, Proteomics 14 (2014) 481-488.

[4] O. Guipaud, M. Benderitter, Protein biomarkers for radiation exposure: towards a proteomic approach as a new investigation tool, Ann. Ist. Super. Sanita 45 (2009) 278-286.

[5] C. Menard, D. Johann, M. Lowenthal, T. Muanza, M. Sproull, S. Ross, J. Gulley, E. Petricoin, C.N. Coleman, G. Whiteley, L. Liotta, K. Camphausen, Discovering clinical biomarkers of ionizing radiation exposure with serum proteomic analysis, Cancer Res. 66 (2006) 1844-1850.

[6] F. Marchetti, M.A. Coleman, I.M. Jones, A.J. Wyrobek, Candidate protein biodosimeters of human exposure to ionizing radiation, Int. J. Radiat. Biol. 82 (2006) 605-639.

[7] J. Lacombe, D. Azria, A. Mange, J. Solassol, Proteomic approaches to identify biomarkers predictive of radiotherapy outcomes, Expert Rev. Proteomics 10 (2013) 33-42.

[8] O. Guipaud, V. Vereycken-Holler, J. Vinh, M. Benderitter, Identification of differentially expressed proteins in serums of skin-irradiated mice; Characterization of potential ionising radiation biomarkers, Mol. Cell. Proteomics 4 (2005) S150-S150.

[9] M. Deperas-Kaminska, A. Bajinskis, M. Marczyk, J. Polanska, P. Wersall, E. Lidbrink, E.A. Ainsbury, O. Guipaud, M. Benderitter, S. Haghdoost, A. Wojcik, Radiation-induced changes in levels of selected proteins in peripheral blood serum of breast cancer patients as a potential triage biodosimeter for large-scale radiological emergencies, Health Phys. 107 (2014) 555-563.

[10] O. Guipaud, Serum and Plasma Proteomics and Its Possible Use as Detector and Predictor of Radiation Diseases, in: D. Leszczynski (Ed.) Radiation Proteomics: The Effects of lonizing and NonIonizing Radiation on Cells and Tissues, Springer, New York, 2013, pp. 61-86.

[11] F. Yang, K.M. Waters, B.-J. Webb-Robertson, M.B. Sowa, C. von Neubeck, J.T. Aldrich, L.M. Markillie, R.M. Wirgau, M.A. Gritsenko, R. Zhao, D.G. Camp, II, R.D. Smith, D.L. Stenoien, Quantitative phosphoproteomics identifies filaggrin and other targets of ionizing radiation in a human skin model, Exp. Dermatol. 21 (2012) 352-357.

[12] P. Beli, N. Lukashchuk, S.A. Wagner, B.T. Weinert, J.V. Olsen, L. Baskcomb, M. Mann, S.P. Jackson, C. Choudhary, Proteomic Investigations Reveal a Role for RNA Processing Factor THRAP3 in the DNA Damage Response, Mol. Cell 46 (2012) 212-225.

[13] D. Winter, J. Seidler, S. Ziv-Lehrman, Y. Shiloh, W.D. Lehmann, Simultaneous Identification and Quantification of Proteins by Differential 0-16/O-18 Labeling and UPLC-MS/MS Applied to Mouse Cerebellar Phosphoproteome Following Irradiation, Anticancer Res. 29 (2009) 4949-4958.

[14] L.K. Povlsen, P. Beli, S.A. Wagner, S.L. Poulsen, K.B. Sylvestersen, J.W. Poulsen, M.L. Nielsen, S. Bekker-Jensen, N. Mailand, C. Choudhary, Systems-wide analysis of ubiquitylation dynamics reveals a key role for PAF15 ubiquitylation in DNA-damage bypass, Nat. Cell Biol. 14 (2012) 1089-1098.

[15] O. Azimzadeh, H. Scherthan, H. Sarioglu, Z. Barjaktarovic, M. Conrad, A. Vogt, J. Calzada-Wack, F. Neff, M. Aubele, C. Buske, M.J. Atkinson, S. Tapio, Rapid proteomic remodeling of cardiac tissue caused by total body ionizing radiation, Proteomics 11 (2011) 3299-3311.

[16] O. Azimzadeh, W. Sievert, H. Sarioglu, R. Yentrapalli, Z. Barjaktarovic, A. Sriharshan, M. Ueffing, D. Janik, M. Aichler, M.J. Atkinson, G. Multhoff, S. Tapio, PPAR Alpha: A Novel Radiation Target in Locally Exposed Mus musculus Heart Revealed by Quantitative Proteomics, J. Proteome Res. 12 (2013) 2700-2714.

[17] T. Chaze, M.-C. Slomianny, F. Milliat, G. Tarlet, T. Lefebvre-Darroman, P. Gourmelon, E. Bey, M. Benderitter, J.-C. Michalski, O. Guipaud, Alteration of the Serum N-glycome of Mice Locally Exposed to High Doses of lonizing Radiation, Mol. Cell. Proteomics 12 (2013) 283-301. 
[18] M. Lee, H.J. Lee, W.D. Seo, K.H. Park, Y.S. Lee, Sialylation of integrin beta1 is involved in radiation-induced adhesion and migration in human colon cancer cells, Intl. J. Rad. Onc. Bio. Phys. 76 (2010) 1528-1536.

[19] M. Lee, H.J. Lee, S. Bae, Y.S. Lee, Protein sialylation by sialyltransferase involves radiation resistance, Mol. Cancer Res. 6 (2008) 1316-1325.

[20] J. Ma, D.P. Han, M. Zhang, C. Chen, B.R. Zhang, Z.H. Zhang, X.H. Wang, S.M. Yang, Y.S. Guo, P. Okunieff, L.R. Zhang, Alteration of Plasma Galactose/N-acetylgalactosamine Level After Irradiation, in: W.J. Welch, F. Palm, D.F. Bruley, D.K. Harrison (Eds.) Oxygen Transport to Tissue Xxxiv, Springer, New York, 2013, pp. 147-153.

[21] P.M. Rudd, R.A. Dwek, Glycosylation: Heterogeneity and the 3D structure of proteins, Crit. Rev. Biochem. Mol. Biol. 32 (1997) 1-100.

[22] J.N. Arnold, M.R. Wormald, R.B. Sim, P.M. Rudd, R.A. Dwek, The impact of glycosylation on the biological function and structure of human immunoglobulins, Annu. Rev. Immunol. 25 (2007) 21-50.

[23] B. Imperiali, S.E. O'Connor, Effect of N-linked glycosylation on glycopeptide and glycoprotein structure, Curr. Opin. Chem. Biol. 3 (1999) 643-649.

[24] P. Van den Steen, P.M. Rudd, R.A. Dwek, G. Opdenakker, Concepts and principles of O-linked glycosylation, Crit. Rev. Biochem. Mol. Biol. 33 (1998) 151-208.

[25] K. Marino, J. Bones, J.J. Kattla, P.M. Rudd, A systematic approach to protein glycosylation analysis: a path through the maze, Nat. Chem. Biol. 6 (2010) 713-723.

[26] H. Geyer, R. Geyer, Strategies for analysis of glycoprotein glycosylation, Biochim. Biophys. Acta 1764 (2006) 1853-1869.

[27] J. Stadlmann, M. Pabst, D. Kolarich, R. Kunert, F. Altmann, Analysis of immunoglobulin glycosylation by LC-ESI-MS of glycopeptides and oligosaccharides, Proteomics 8 (2008) 2858-2871.

[28] H.J. An, J.W. Froehlich, C.B. Lebrilla, Determination of glycosylation sites and site-specific heterogeneity in glycoproteins, Curr. Opin. Chem. Biol. 13 (2009) 421-426.

[29] O. Guipaud, V. Holler, V. Buard, G. Tarlet, N. Royer, J. Vinh, M. Benderitter, Time-course analysis of mouse serum proteome changes following exposure of the skin to ionizing radiation, Proteomics 7 (2007) 3992-4002.

[30] E. Toth, O. Ozohanics, B. Bobaly, A. Gomory, A. Jeko, L. Drahos, K. Vekey, HPLC enrichment/isolation of proteins for post-translational modification studies from complex mixtures, J. Pharm. Biomed. Anal. 98 (2014) 393-400.

[31] O. Ozohanics, L. Turiak, A. Puerta, K. Vekey, L. Drahos, High-performance liquid chromatography coupled to mass spectrometry methodology for analyzing site-specific $\mathrm{N}$-glycosylation patterns, J. Chromatogr. A 1259 (2012) 200-212.

[32] O. Ozohanics, J. Krenyacz, K. Ludanyi, F. Pollreisz, K. Vekey, L. Drahos, GlycoMiner: a new software tool to elucidate glycopeptide composition, Rapid. Commun. Mass Spectrom. 22 (2008) 3245-3254.

[33] J. Benicky, M. Sanda, P. Pompach, J. Wu, R. Goldman, Quantification of Fucosylated Hemopexin and Complement Factor H in Plasma of Patients with Liver Disease, Anal. Chem. 86 (2014) 1071610723. 


\section{Appendices}

Table A: List of selected glycoforms for quantitative study and their relative

\section{abundances.}

List of selected glycoforms for quantitative study and their relative abundances in sample "A" averaged over the 10 patients' samples.

\begin{tabular}{|c|c|c|c|}
\hline $\begin{array}{l}\text { Uniprot entry } \\
\text { name }\end{array}$ & $\begin{array}{c}\text { Glycopeptide sequence } \\
\text { sugar type }\end{array}$ & $\begin{array}{c}\text { Relative } \\
\text { abundances }\end{array}$ & $\begin{array}{c}\mathrm{m} / \mathrm{z} \\
\text { charge state: } 3+\end{array}$ \\
\hline APOH_HUMAN & LGNWSAMPSCK_BiSOFO & 0,0016 & 958.3873 \\
\hline APOH_HUMAN & LGNWSAMPSCK_BiS1F0 & 0,0568 & 1055.4191 \\
\hline APOH_HUMAN & LGNWSAMPSCK_BiS1F1 & 0,0055 & 1104.1050 \\
\hline APOH_HUMAN & LGNWSAMPSCK_BiS2FO & 0,1797 & 1152.4509 \\
\hline APOH_HUMAN & LGNWSAMPSCK_BiS2F1 & 0,0085 & 1201.1368 \\
\hline APOH_HUMAN & LGNWSAMPSCK_TriS1F0 & 0,0022 & 1177.1298 \\
\hline APOH_HUMAN & LGNWSAMPSCK_TriS2F0 & 0,0058 & 1274.1616 \\
\hline APOH_HUMAN & LGNWSAMPSCK_TriS2F1 & 0,0034 & 1322.8476 \\
\hline APOH_HUMAN & LGNWSAMPSCK_TriS3F0 & 0,0088 & 1371.1934 \\
\hline APOH_HUMAN & LGNWSAMPSCK_TriS3F1 & 0,0091 & 1419.8794 \\
\hline APOH_HUMAN & VYKPSAGNNSLYR_BiS1F0 & 0,0070 & 1128.1486 \\
\hline APOH_HUMAN & VYKPSAGNNSLYR_BiS1F1 & 0,0012 & 1176.8346 \\
\hline APOH_HUMAN & VYKPSAGNNSLYR_BiS2F0 & 0,1638 & 1225.1804 \\
\hline APOH_HUMAN & VYKPSAGNNSLYR_BiS2F1 & 0,0518 & 1273.8664 \\
\hline APOH_HUMAN & VYKPSAGNNSLYR_TriS2F0 & 0,0034 & 1346.8912 \\
\hline APOH_HUMAN & VYKPSAGNNSLYR_TriS3F0 & 0,0234 & 1443.9230 \\
\hline APOH_HUMAN & VYKPSAGNNSLYR_TriS3F1 & 0,0212 & 1492.6089 \\
\hline CFAH_HUMAN & ISEENETTCYMGK_BiS1F0 & 0,0121 & 1159.1142 \\
\hline CFAH_HUMAN & ISEENETTCYMGK_BiS2F0 & 0,0740 & 1256.1460 \\
\hline CFAH_HUMAN & ISEENETTCYMGK_BiS2F1 & 0,0021 & 1304.8319 \\
\hline CFAH_HUMAN & ISEENETTCYMGK_TriS2F0 & 0,0028 & 1377.8567 \\
\hline CFAH_HUMAN & ISEENETTCYMGK_TriS3FO & 0,0040 & 1474.8885 \\
\hline CFAH_HUMAN & MDGASNVTCINSR_BiS1F0 & 0,0139 & 1113.4391 \\
\hline CFAH_HUMAN & MDGASNVTCINSR_BiS2F0 & 0,0944 & 1210.4709 \\
\hline CFAH_HUMAN & MDGASNVTCINSR_BiS2F1 & 0,0017 & 1259.1569 \\
\hline CFAH_HUMAN & IPCSQPPQIEHGTINSSR_BiS1F0 & 0,0187 & 1312.2262 \\
\hline CFAH_HUMAN & IPCSQPPQIEHGTINSSR_BiS1F1 & 0,0035 & 1360.9121 \\
\hline CFAH_HUMAN & IPCSQPPQIEHGTINSSR_BiS2FO & 0,1070 & 1409.2580 \\
\hline CFAH_HUMAN & IPCSQPPQIEHGTINSSR_BiS2F1 & 0,0071 & 1457.9439 \\
\hline CFAH_HUMAN & IPCSQPPQIEHGTINSSR_TriS3F0 & 0,0009 & 1628.0005 \\
\hline KNG1_HUMAN & LNAENNATFYFK_BiS2F0 & 0,0136 & 1212.8258 \\
\hline KNG1_HUMAN & LNAENNATFYFK_BiS2F1 & 0,0030 & 1261.5117 \\
\hline KNG1_HUMAN & LNAENNATFYFK_TriS2F0 & 0,0012 & 1334.5365 \\
\hline KNG1_HUMAN & LNAENNATFYFK_TriS2F1 & 0,0022 & 1383.2225 \\
\hline
\end{tabular}




\begin{tabular}{|c|c|c|c|}
\hline KNG1_HUMAN & LNAENNATFYFK_TriS3F0 & 0,0051 & 1431.5683 \\
\hline KNG1_HUMAN & LNAENNATFYFK_TriS3F1 & 0,0113 & 1480.2543 \\
\hline KNG1_HUMAN & ITYSIVQTNCSK_BiS1F0 & 0,0018 & 1109.7986 \\
\hline KNG1_HUMAN & ITYSIVQTNCSK_BiS2F0 & 0,0208 & 1206.8304 \\
\hline KNG1_HUMAN & ITYSIVQTNCSK_BiS2F1 & 0,0008 & 1255.5164 \\
\hline KNG1_HUMAN & ITYSIVQTNCSK_TriS2FO & 0,0032 & 1328.5411 \\
\hline KNG1_HUMAN & ITYSIVQTNCSK_TriS2F1 & 0,0036 & 1377.2271 \\
\hline KNG1_HUMAN & ITYSIVQTNCSK_TriS3FO & 0,0151 & 1425.5730 \\
\hline KNG1_HUMAN & ITYSIVQTNCSK_TriS3F1 & 0,0183 & 1474.2589 \\
\hline KNG1_HUMAN & YNSQNQSNNQFVLYR_BiS2FO & 0,0049 & 1360.5550 \\
\hline TRFE_HUMAN & CGLVPVLAENYNK_BiSOFO & 0,0003 & 1033.7826 \\
\hline TRFE_HUMAN & CGLVPVLAENYNK_BiS1F0 & 0,0366 & 1130.8144 \\
\hline TRFE_HUMAN & CGLVPVLAENYNK_BiS1F1 & 0,0013 & 1179.5003 \\
\hline TRFE_HUMAN & CGLVPVLAENYNK_BiS2F0 & 0,1522 & 1227.8462 \\
\hline TRFE_HUMAN & CGLVPVLAENYNK_BiS2F1 & 0,0044 & 1276.5321 \\
\hline TRFE_HUMAN & CGLVPVLAENYNK_TriS1FO & 0,0047 & 1252.5251 \\
\hline TRFE_HUMAN & CGLVPVLAENYNK_TriS2FO & 0,0050 & 1349.5569 \\
\hline TRFE_HUMAN & CGLVPVLAENYNK_TriS3F0 & 0,0019 & 1446.5887 \\
\hline TRFE_HUMAN & QQQHLFGSNVTDCSGNFCLFR_BiS1F0 & 0,0077 & 1476.9386 \\
\hline TRFE_HUMAN & QQQHLFGSNVTDCSGNFCLFR_BiS1F1 & 0,0020 & 1525.6245 \\
\hline TRFE_HUMAN & QQQHLFGSNVTDCSGNFCLFR_BiS2FO & 0,1055 & 1573.9704 \\
\hline TRFE_HUMAN & QQQHLFGSNVTDCSGNFCLFR_BiS2F1 & 0,0088 & 1622.6563 \\
\hline TRFE_HUMAN & QQQHLFGSNVTDCSGNFCLFR_TriS2F0 & 0,0004 & 1695.6811 \\
\hline TRFE_HUMAN & QQQHLFGSNVTDCSGNFCLFR_TriS3F0 & 0,0028 & 1792.7129 \\
\hline TRFE_HUMAN & QQQHLFGSNVTDCSGNFCLFR_TriS3F1 & 0,0024 & 1841.3989 \\
\hline FETUA_HUMAN & VCQDCPLLAPLNDTR_BiS1F0 & 0,0009 & 1229.1794 \\
\hline FETUA_HUMAN & VCQDCPLLAPLNDTR_BiS2F0 & 0,0122 & 1326.2112 \\
\hline FETUA_HUMAN & AALAAFNAQNNGSNFQLEEISR_BiS1F0 & 0,0005 & 1426.9482 \\
\hline FETUA_HUMAN & AALAAFNAQNNGSNFQLEEISR_BiS2FO & 0,0095 & 1523.9800 \\
\hline FETUA_HUMAN & AALAAFNAQNNGSNFQLEEISR_BiS2F1 & 0,0019 & 1572.6660 \\
\hline HPT_HUMAN & MVSHHNLTTGATLINEQWLLTTAK_BiS1F0 & 0,0109 & 1531.6946 \\
\hline HPT_HUMAN & MVSHHNLTTGATLINEQWLLTTAK_BiS2F0 & 0,0264 & 1628.7264 \\
\hline HPT_HUMAN & VVLHPNYSQVDIGLIK_BiS1F0 & 0,0369 & 1236.9009 \\
\hline HPT_HUMAN & VVLHPNYSQVDIGLIK_BiS2FO & 0,2626 & 1333.9327 \\
\hline HPT_HUMAN & VVLHPNYSQVDIGLIK_BiS2F1 & 0,0126 & 1382.6187 \\
\hline HPT_HUMAN & VVLHPNYSQVDIGLIK_TriS1F0 & 0,0130 & 1358.6117 \\
\hline HPT_HUMAN & VVLHPNYSQVDIGLIK_TriS2F0 & 0,0121 & 1455.6435 \\
\hline HPT_HUMAN & VVLHPNYSQVDIGLIK_TriS3FO & 0,0179 & 1552.6753 \\
\hline HPT_HUMAN & VVLHPNYSQVDIGLIK_TriS3F1 & 0,0050 & 1601.3612 \\
\hline A1AG2_HUMAN & LVPVPITNATLDR_BiS1F0 & 0,0034 & 1108.1691 \\
\hline A1AG2_HUMAN & LVPVPITNATLDR_BiS2F0 & 0,0208 & 1205.2009 \\
\hline A1AG2_HUMAN & LVPVPITNATLDR_TriS2F0 & 0,0152 & 1326.9117 \\
\hline A1AG2_HUMAN & LVPVPITNATLDR_TriS2F1 & 0,0090 & 1375.5976 \\
\hline A1AG2_HUMAN & LVPVPITNATLDR_TriS3F0 & 0,0338 & 1423.9435 \\
\hline A1AG2_HUMAN & LVPVPITNATLDR_TriS3F1 & 0,0256 & 1472.6294 \\
\hline
\end{tabular}




\begin{tabular}{|llll|} 
A1AG2_HUMAN & LVPVPITNATLDR_TetraS2F0 & 0,0006 & 1448.6224 \\
\hline A1AG1_HUMAN & LVPVPITNATLDQITGK_BiS2F0 & 0,0085 & 1328.9361 \\
\hline A1AG1_HUMAN & LVPVPITNATLDQITGK_TriS2FO & 0,0060 & 1450.6469 \\
\hline A1AG1_HUMAN & LVPVPITNATLDQITGK_TriS2F1 & 0,0027 & 1499.3328 \\
\hline A1AG1_HUMAN & LVPVPITNATLDQITGK_TriS3F0 & 0,0168 & 1547.6787 \\
\hline A1AG1_HUMAN & LVPVPITNATLDQITGK_TriS3F1 & 0,0120 & 1596.3647 \\
\hline A1AG1,2_HUMAN & NEEYNK_TriS3F0 & 0,0009 & 1219.7873 \\
\hline A1AG1,2_HUMAN & NEEYNK_TriS3F1 & 0,0008 & 1268.4732 \\
\hline A1AG1,2_HUMAN & SVQEIQATFFYFTPNK_BiS2F0 & 0,0032 & 1375.5803 \\
\hline A1AG1,2_HUMAN & SVQEIQATFFYFTPNK_TriS2F0 & 0,0005 & 1497.2910 \\
\hline A1AG1_HUMAN & QDQCIYNTTYLNVQR_BiS2F0 & 0,0022 & 1374.2279 \\
\hline A1AG1_HUMAN & QDQCIYNTTYLNVQR_TriS2F0 & 0,0033 & 1495.9386 \\
\hline A1AG1_HUMAN & QDQCIYNTTYLNVQR_TriS2F1 & 0,0016 & 1544.6246 \\
\hline A1AG1_HUMAN & QDQCIYNTTYLNVQR_TriS3F0 & 0,0082 & 1592.9704 \\
\hline A1AG1_HUMAN & QDQCIYNTTYLNVQR_TriS3F1 & 0,0076 & 1641.6564 \\
\hline A1AG1_HUMAN & QDQCIYNTTYLNVQR_TetraS1F0 & 0,0008 & 1520.6176 \\
\hline A1AG1_HUMAN & QDQCIYNTTYLNVQR_TetraS2F0 & 0,0072 & 1617.6494 \\
\hline A1AG1_HUMAN & QDQCIYNTTYLNVQR_TetraS2F1 & 0,0031 & 1666.3353 \\
\hline A1AG1_HUMAN & QDQCIYNTTYLNVQR_TetraS3F0 & 0,0054 & 1714.6812 \\
\hline A1AG1_HUMAN & QDQCIYNTTYLNVQR_TetraS3F1 & 0,0031 & 1763.3671 \\
\hline
\end{tabular}


Fig. A: Site-specific glycosylation pattern of alpha-2-HS-glycoprotein and serotransferrin.

Site-specific glycosylation pattern of alpha-2-HS-glycoprotein and serotransferrin in case of "A", "B" and "C" samples for one individual.

Alpha-2-HS-glycoprotein:

Site 1: ${ }^{145}$ VCQDCPLLAPL $^{156} \mathrm{NDTR}^{159}$, Site $2:{ }^{166} \mathrm{AALAAFNAQN}^{176} \mathrm{NGSNFQLEEISR}^{187}$ Serotransferrin:

Site 1: ${ }^{421}$ CGLVPVLAENY ${ }^{432} \mathrm{NK}^{433}$, Site $2:{ }^{622} \mathrm{QQQHLFGS}^{630} \mathrm{NVTDCSGNFCLFR}^{642}$

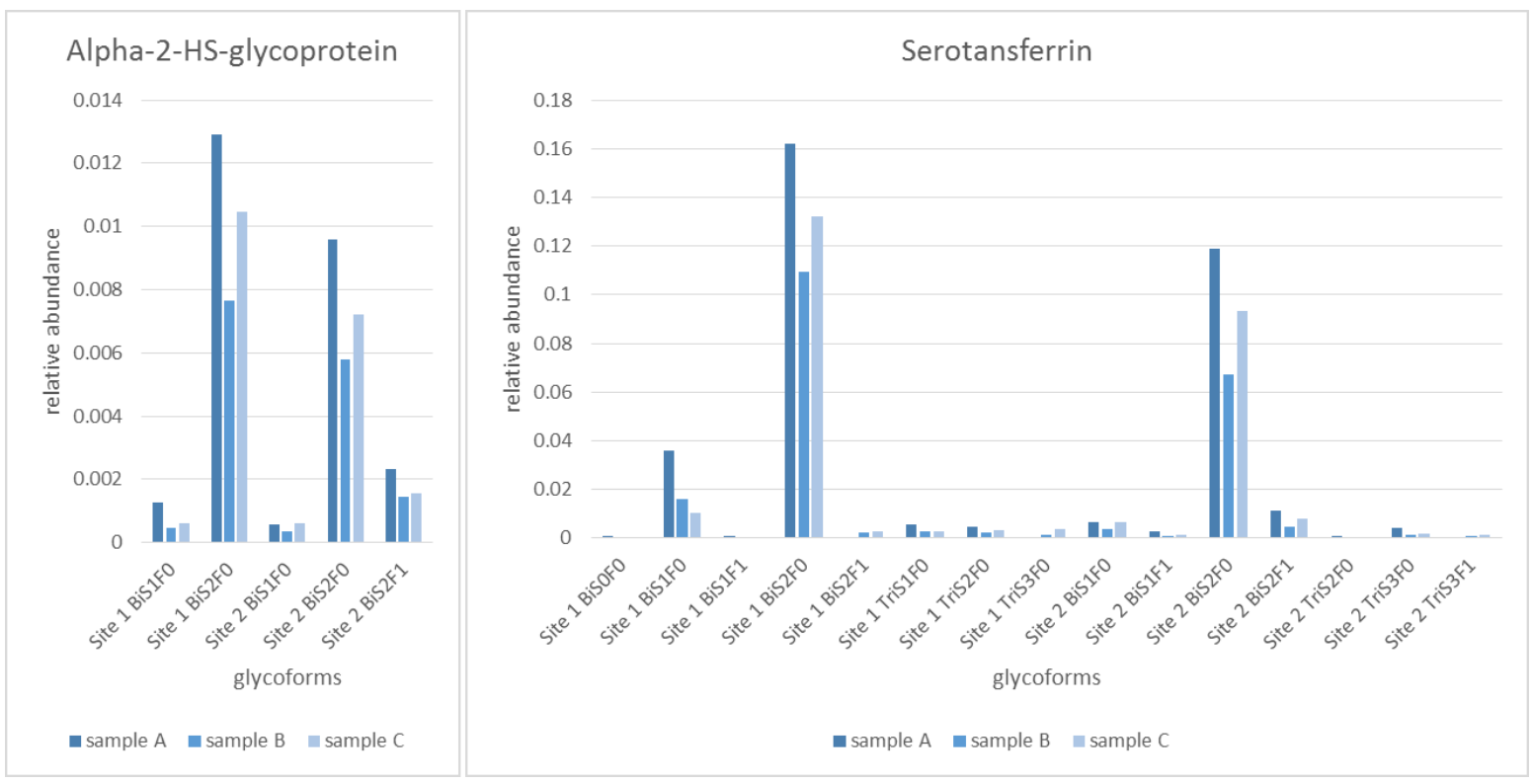


Fig. B: Correlation between $\mathrm{B} / \mathrm{A}$ and $\mathrm{C} / \mathrm{A}$ ratios.

Correlation between $\mathrm{B} / \mathrm{A}$ and $\mathrm{C} / \mathrm{A}$ ratios - changes in the abundance ratio of various glycoforms between samples B and A; and that between $\mathrm{C}$ and $\mathrm{A}$ for one individual.

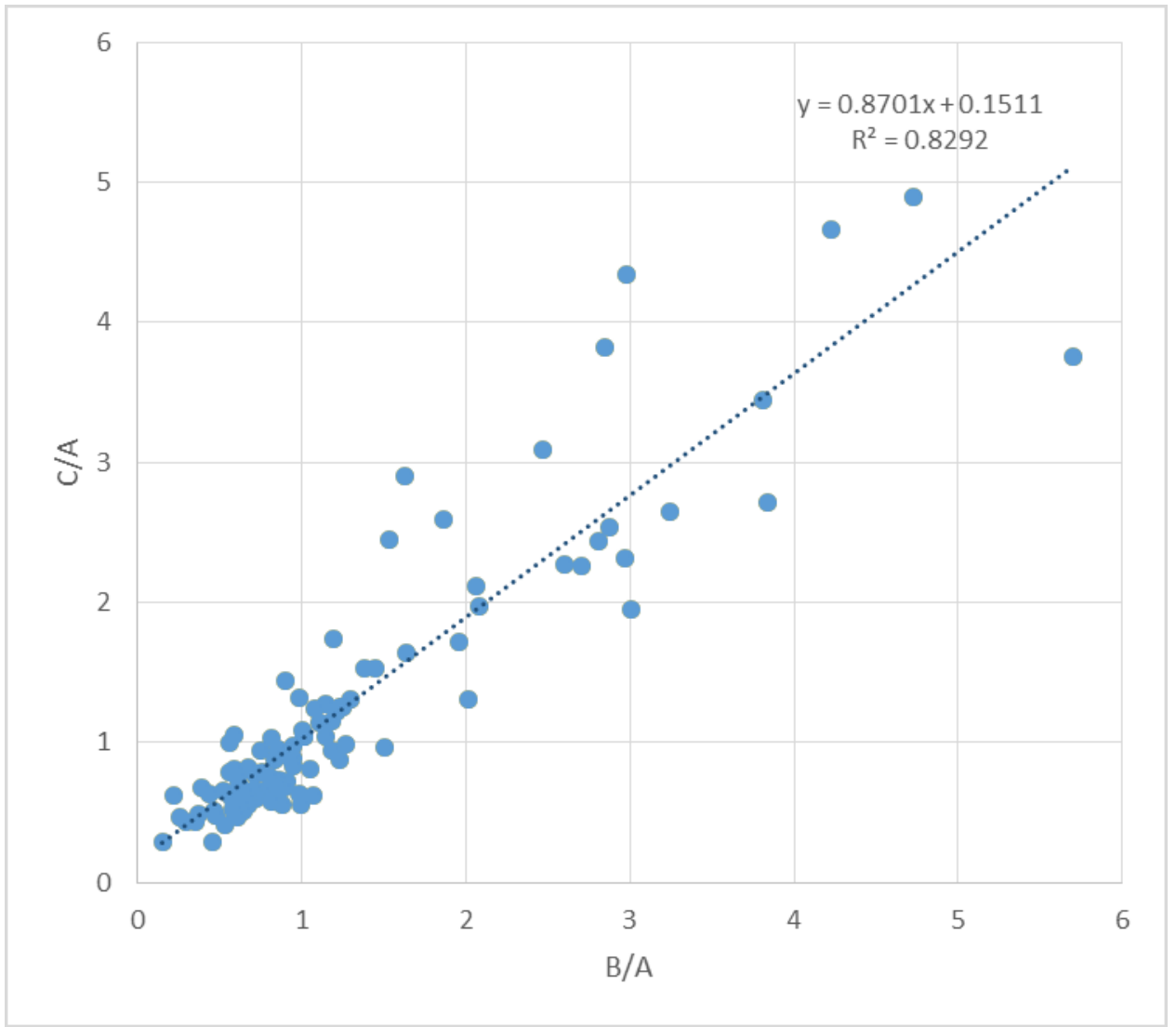


Fig. C: B/A and the corresponding C/A abundance ratios for all glycoforms and individuals.

$\mathrm{B} / \mathrm{A}$ (blue squares) and the corresponding $\mathrm{C} / \mathrm{A}$ (orange open circles) abundance ratios measured for various glycoforms and individuals. Data are arranged in a decreasing series of $\mathrm{B} / \mathrm{A}$ values.

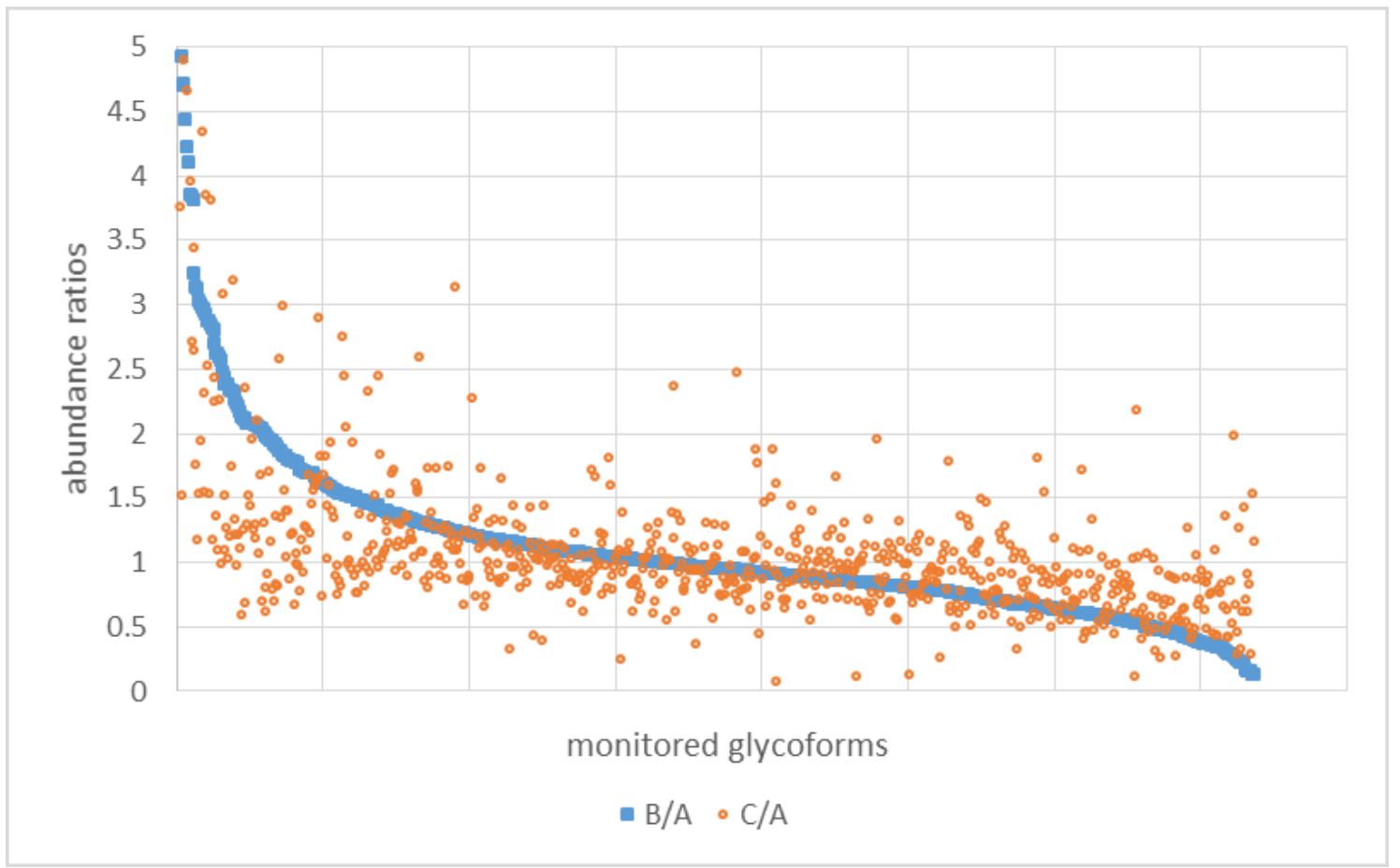

